\title{
Rats Markedly Escalate Their Intake and Show a Persistent Susceptibility to Reinstatement Only When Cocaine Is Injected Rapidly
}

\author{
Ken T. Wakabayashi, ${ }^{1}$ Mark J. Weiss, ${ }^{2}$ Kristen N. Pickup, ${ }^{2}$ and Terry E. Robinson ${ }^{1,2}$ \\ ${ }^{1}$ Neuroscience Graduate Program and ${ }^{2}$ Department of Psychology, The University of Michigan, Ann Arbor, Michigan 48109
}

When drugs enter the brain rapidly, liability for addiction is increased, but why this is the case is not well understood. Here we examined the influence of varying the speed of intravenous cocaine delivery on self-administration behavior in rats given limited or extended opportunity to take drug. The speed of cocaine delivery had no effect on self-administration behavior when rats were given only $1 \mathrm{~h}$ each day to take cocaine. When given sixfold more time to take cocaine, rats that received cocaine rapidly $(5-45 \mathrm{~s})$ increased their total intake eightfold. However, rats that received cocaine more slowly $(>90 \mathrm{~s})$ did not avail themselves of the opportunity to take much more drug: they increased their intake only twofold. Furthermore, when tested $45 \mathrm{~d}$ after the last self-administration session, a drug-priming injection reinstated drug-seeking behavior only in rats that in the past had cocaine injected rapidly $(5 \mathrm{~s})$, and this was associated with a persistent suppression in the ability of cocaine to induce immediate early gene expression. Cocaine may be potentially more addictive when it reaches the brain rapidly because (1) this promotes a marked escalation in intake and (2) it renders individuals more susceptible to relapse long after the discontinuation of drug use. This is presumably because the rapid uptake of drug to the brain preferentially promotes persistent changes in brain systems that regulate motivation for drug, and continuing exposure to large amounts of drug produces a vicious cycle of additional maladaptive changes in brain and behavior.

\section{Introduction}

Drugs or drug formulations that reach the brain rapidly are potentially more addictive than those that reach the brain relatively slowly (Hatsukami and Fischman, 1996). For example, people who initiate cocaine use through routes that lead to its rapid uptake into brain are more likely to become addicted (Gorelick, 1998; O'Brien and Anthony, 2005), but why this is the case is not well understood. One possibility is that the euphorigenic effects of cocaine are greatest when it is delivered rapidly (Resnick et al., 1977; Abreu et al., 2001; Nelson et al., 2006), which may enhance its reinforcing effects, promoting continued use (Gorelick, 1998). Alternatively, rapid drug delivery is more effective in producing forms of neurobehavioral plasticity that may promote the transition to addiction (Samaha et al., 2002). The rapid delivery of drugs such as cocaine and nicotine greatly enhances their neurobiological effects (Brown and Kiyatkin, 2005; Samaha and Robinson, 2005), including their ability to induce immediate early genes in mesocorticolimbic structures (Samaha et al., 2004, 2005), which is thought to be an initial step leading to forms of drug-induced plasticity important for addiction (Nestler, 2001; Zhang et al., 2005, 2006).

Received May 12, 2010; revised June 30, 2010; accepted July 7, 2010.

This research was supported by National Institute on Drug Abuse (NIDA) Grant R37 DA004294 (T.E.R.) and NIDA Individual National Research Service Award F31 DA021060 (K.T.W.). We thank Drs. Hans Crombag, Sheila M. Reynolds, and Anna-Noel Samaha for helpful discussions.

Correspondence should be addressed to Dr. Terry E. Robinson, 530 Church Street, East Hall, Psychology, Ann Arbor, MI 48109-1043. E-mail: ter@umich.edu.

DOI:10.1523/JNEUROSCI.2524-10.2010

Copyright $\odot 2010$ the authors $\quad$ 0270-6474/10/3011346-10\$15.00/0
Despite the profound influence of rate of drug delivery on brain and behavior, evidence for a similar effect on the willingness of animals to self-administer drugs is mixed. In monkeys, increasing the rate of cocaine delivery facilitates self-administration behavior (Balster and Schuster, 1973; Kato et al., 1987; Panlilio et al., 1998; Woolverton and Wang, 2004), but in some studies, such effects were evident only when the rate of infusion (ROI) was so slow it would result in lower levels of drug in the brain (Balster and Schuster, 1973; Kato et al., 1987; Panlilio et al., 1998; Woolverton and Wang, 2004). In rats, when amphetamine or cocaine is delivered between 5 and $100 \mathrm{~s}$, a range that produces the same peak brain levels of drug but influences susceptibility to sensitization, there is very little, if any, effect on the acquisition or maintenance of self-administration behavior, progressive ratio performance, or the reinstatement of drug-seeking behavior (Pickens et al., 1969; Liu et al., 2005; Crombag et al., 2008). During acquisition, rats do discriminate and preferentially select faster rates of cocaine within this range (Schindler et al., 2009), but it not clear whether this effect is sufficient to account for the influence of rate of drug delivery on susceptibility to addiction.

There are now a number of reports that rats develop addiction-like symptoms only when they are given extended access to cocaine (Ahmed and Koob, 1998; Ahmed et al., 2002; Deroche-Gamonet et al., 2004; Vanderschuren and Everitt, 2004; Pelloux et al., 2007; Ben-Shahar et al., 2008), but previous studies on rate of drug delivery used limited access procedures (Pickens et al., 1969; Crombag et al., 2008). We hypothesized, therefore, that, if given extended access to cocaine, the degree to which rats would increase drug intake, and their later propensity for rein- 


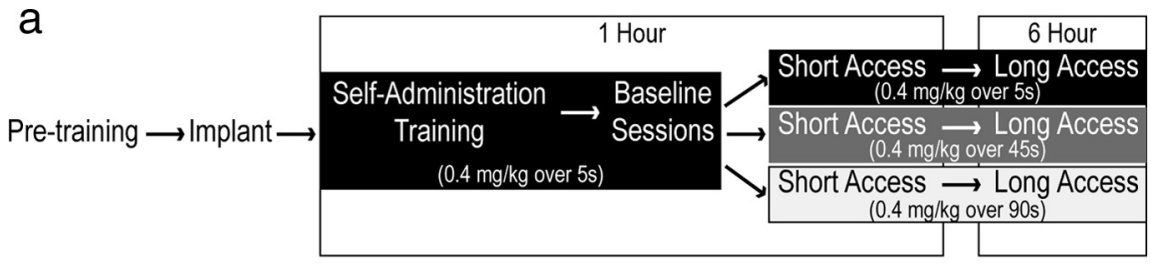

b

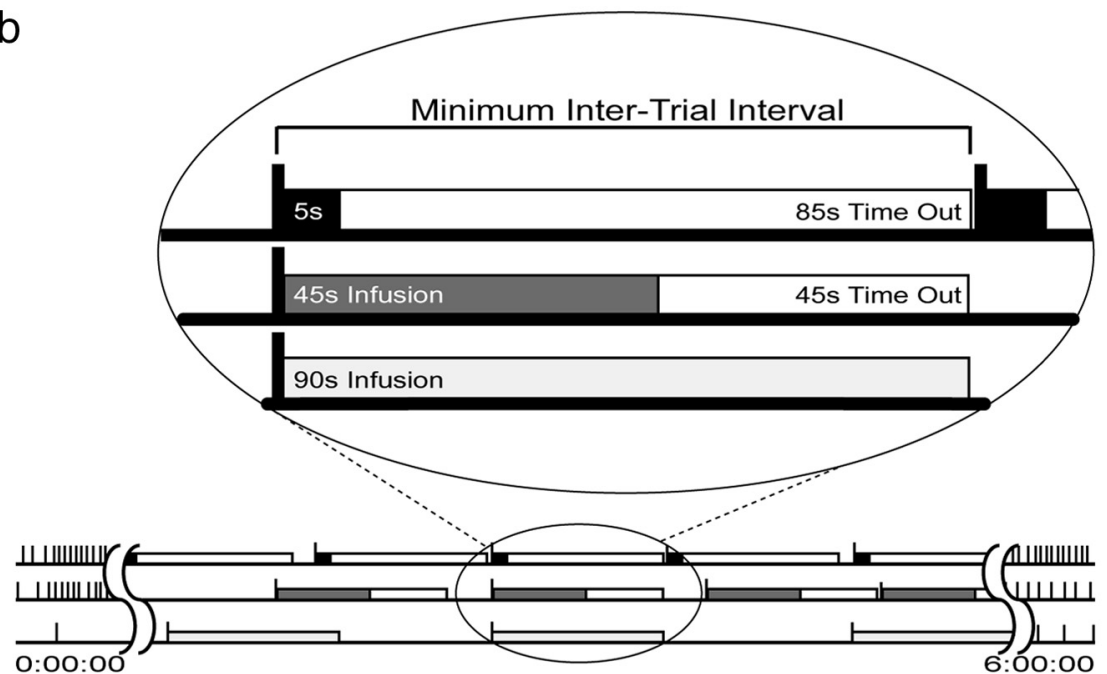

\section{$\mathrm{C}$}

\section{History of $5 \mathrm{~s}$ LgA}

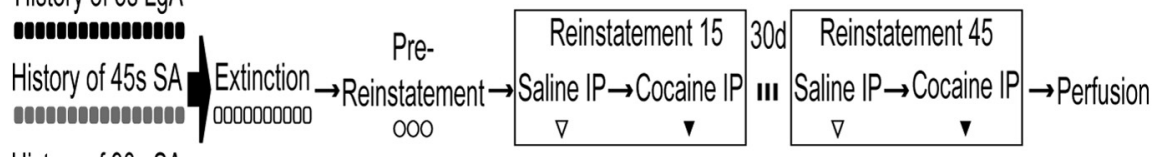

History of $90 \mathrm{~s} S \mathrm{~A}$

0000000000000000

Figure 1. $\quad \boldsymbol{a}$, An illustration of the self-administration (SA) experimental design. $\boldsymbol{b}$, A representation of a typical long-access session for rats in the 5, 45, and 90 s groups. In the bottom, the length of the session is represented by a horizontal line. Vertical tick marks represent nose pokes in which rats received an infusion of cocaine. For clearer comparison, the inset circle shows the infusion lengths and timeout intervals of the three groups in the experiment. The duration of the infusion and following timeout interval is indicated for each group. Note that the number of opportunities to self-administer an injection is exactly the same in all groups because the timeout periods varied accordingly. c, An illustration of the extinction-reinstatement experimental design. Icons depict the number of sessions for each condition.

statement, may vary depending on how rapidly cocaine was delivered.

\section{Materials and Methods}

Subjects and housing. A total of 61 male Wistar rats (Harlan) weighing between 225 and $250 \mathrm{~g}$ on arrival were used. Rats were individually housed in a climate-controlled animal colony maintained on a 14/10 h light/dark cycle (lights on at 8:00 A.M.), with food and water available ad libitum. All procedures were approved by the University of Michigan Committee on the Use and Care of Animals.

Rats were included in the experiment only if they acquired and maintained stable self-administration behavior and completed all phases of testing. A total of 46 rats completed the self-administration portion of the study. Rats were removed from the experiment mainly because they did not acquire self-administration or their catheters lost patency before completing the experiment. This did not impact one group more than the others. In the extinction-reinstatement portion of the experiment, one rat in the 90 s group died during the course of the $30 \mathrm{~d}$ withdrawal period and was removed from this analysis.

Self-administration apparatus. Behavioral training and testing occurred in operant chambers located in a different room than the rat's home cage. The chambers measured $22 \times 18 \times 13 \mathrm{~cm}$ (MED Associates) and were located inside larger sound-attenuating cabinets, which were continuously venti- lated by a fan that also provided background noise. Each operant chamber was outfitted with two illuminated infrared nose-poke ports surrounding a centrally located pellet dispenser and pellet cup, and a red house light was positioned on the opposite wall. The floor of the chamber consisted of a grid floor with corncob bedding below the grids, which was replaced daily. Chambers were controlled by a personal computer (Intel Core Duo E4500) running Med-PC version IV.

Each operant chamber was equipped with an infusion pump consisting of a $10 \mathrm{ml}$ syringe installed in a PHM-100 pump (MED Associates) attached via a length of Tygon microbore tubing to an Instech-Solomon liquid swivel mounted on a counterbalanced arm. On training and test days, rat's catheters were attached to the liquid swivel via another length of polyethylene tubing inserted within a flexible steel sheath. The rate of drug delivery was varied by installing motors (model R-DE; MED Associates) capable of delivering a $50 \mu \mathrm{l}$ infusion over $4.5 \mathrm{~s}$ ( $2 \mathrm{rpm}, 0.661 \mathrm{ml} / \mathrm{min}), 45.4 \mathrm{~s}$ (0.2 rpm, $0.066 \mathrm{ml} / \mathrm{min})$, or $90.8 \mathrm{~s}(0.1 \mathrm{rpm}, 0.033 \mathrm{ml} / \mathrm{min})$. In referring to these groups, the rates are "rounded," and we will refer to groups receiving cocaine over 5,45 , or $90 \mathrm{~s}$. Before each use, the apparatus was flushed with a $20 \%$ ethanol aqueous solution (v/v) to ensure adequate liquid flow through the swivel and lines. Additionally, every $20 \mathrm{~d}$, the infusion efflux delivered by the apparatus was volumetrically measured.

Pretraining. An illustration of the general self-administration experimental design is shown in Figure 1a. To facilitate the acquisition of cocaine self-administration, rats underwent operant training using a food reward before jugular catheterization. On the first day, rats were habituated to the operant chamber, and one food pellet (45 mg banana-flavored Dustless Precision Pellets; Bio-Serv) was delivered into the pellet cup at a pseudorandom interval approximately every $30 \mathrm{~s}$ during a $30 \mathrm{~min}$ session. On the next $3 \mathrm{~d}$, rats were trained to nose poke for food reward using a continuous schedule of reinforcement [fixed ratio 1 (FR1)]. At the start of each session, the house light was turned on and the "active" nose-poke port was illuminated for $20 \mathrm{~s}$. Responses in the active port resulted in the delivery of one pellet. Responses in the "inactive" port did not have any programmed consequences. Rats were then transitioned to an FR2 schedule for a minimum of $3 \mathrm{~d}$. We used food pretraining because, during cocaine self-administration, no explicit cue was associated with drug delivery (see below), which retards the acquisition of this behavior, and so we used food pretraining to help ameliorate this situation.

Catheter construction and surgical procedures. Chronically indwelling jugular catheters with a dead volume of $24-26 \mu$ l were placed into rats using a procedure similar to that described previously (Weeks, 1972; Crombag et al., 1996; Samaha et al., 2002). While not in use, catheters were capped with obdurators. Briefly, rats were anesthetized with ketamine/xylazine (100 and $10 \mathrm{mg} / \mathrm{kg}$, i.p.). The backport was secured between the rat's shoulder blades, whereas the silicon end of the catheter was inserted into the left or right external jugular vein. Catheters were then filled with $0.1 \mathrm{ml}$ solution of 10 $\mathrm{mg} / \mathrm{ml}$ gentamicin sulfate (Vedco), in $0.9 \%$ sterile bacteriostatic saline to minimize infections and catheter occlusions.

Rats were allowed to recover for a minimum of $4 \mathrm{~d}$. Starting the day after the surgery, catheters were flushed manually once per day with 0.2 $\mathrm{ml}$ of the gentamicin solution. Every $7 \mathrm{~d}$, rats were infused intravenously with $0.2 \mathrm{ml}$ of sodium thiopental solution $(20 \mathrm{mg} / \mathrm{ml}$, dissolved in sterile water; Hospira) to assess catheter patency. Rats that did not become 
ataxic within 5-10 s were removed from the study. Rats did not undergo self-administration training on their catheter patency test days.

Drugs and self-administration training. Cocaine hydrochloride (National Institutes of Drug Abuse, Bethesda, MD) was prepared in a $0.9 \%$ sterile saline solution. During self-administration sessions, rats received infusions consisting of $0.4 \mathrm{mg} / \mathrm{kg}$ cocaine (weight of the salt) in a volume of $50 \mu \mathrm{l}$. The unit dose was adjusted every $4 \mathrm{~d}$.

After recovery from surgery, rats were reacclimatized to the operant chamber by an additional session with an FR2 response requirement for a food pellet. The following day, all rats began daily cocaine selfadministration training sessions. All training sessions were $1 \mathrm{~h}$ long, and, in all training sessions, all rats received cocaine delivered over $5 \mathrm{~s}$. Before each session, catheters were flushed with $0.2 \mathrm{ml}$ of the gentamicin solution and then attached to the infusion apparatus. After an experimenterinitiated command, the infusion pumps were activated to fill the dead volume of the catheters before the start of session. Once catheters were filled, the session began with the illumination of the house light and a $20 \mathrm{~s}$ illumination of the active nose-poke port. Initially, rats were trained on a continuous reinforcement schedule (FR1) receiving cocaine, followed by an unsignaled $20 \mathrm{~s}$ timeout interval, in which additional responses were recorded but had no consequences. Note, therefore, that there was no cue explicitly paired with drug delivery, because this would have introduced a confound when the rate of drug delivery was subsequently varied (see below). Once rats were responding above a minimum training criterion (two or more injections per session, twice as many active vs inactive nose pokes) for 2 consecutive days, the response requirement was increased to an FR2 schedule of reinforcement. After achieving stable performance above the minimum training criterion at this schedule for 2 consecutive days, the timeout interval in subsequent daily sessions was lengthened from 20 to $45 \mathrm{~s}$, then $63 \mathrm{~s}$, and finally $85 \mathrm{~s}$. The reason for increasing the final timeout period to $85 \mathrm{~s}$ was so that, in subsequent sessions using different rates of infusion, the total number of infusions possible for all subjects in all groups would remain the same. That is, regardless of infusion rate, all rats could only take one injection every $90 \mathrm{~s}$ (Fig. $1 b$ ).

Influence of rate of infusion: short-access $(1 \mathrm{~h})$ sessions. After acquiring cocaine self-administration on an FR2 schedule of reinforcement during $1 \mathrm{~h}$ sessions in which cocaine was injected over $5 \mathrm{~s}$ with an $85 \mathrm{~s}$ timeout interval (this is referred to as "baseline"), rats were assigned to one of three groups that differed in rate of cocaine delivery (Fig. $1 a, b)$. One group $(5 \mathrm{~s}$, $n=14$ ) continued to receive cocaine infusions at the training rate of infusion and with the same timeout interval. A second group $(n=18)$ received their infusions over $45 \mathrm{~s}$, followed by a $45 \mathrm{~s}$ timeout interval. The last group $(n=$ 14) was infused with cocaine delivered over $90 \mathrm{~s}$, with no timeout interval (Fig. 1b). Individual subjects were assigned in such a way that the mean number of infusions achieved during the last $2 \mathrm{~d}$ of baseline training was balanced between groups. Rats were tested for three daily sessions at their respective new rates during $1 \mathrm{~h}$ short-access (ShA) sessions.

Influence of rate of infusion: long-access ( $6 h$ ) sessions. From day 4 to day 20 of self-administration testing, the length of each session for all groups was increased to $6 \mathrm{~h} / \mathrm{d}$, because this procedure is reported to lead to the development of addiction-like symptoms (Ahmed and Koob, 1998, 1999; Ahmed et al., 2002). Once the sessions were extended, they all began at 11:00 A.M. to reduce the influence of circadian rhythms on self-administration performance. Rats were removed from the study during long-access ( $\operatorname{LgA}$ ) sessions if they failed to maintain a median number of infusions $>2.5$ and a median active/inactive nose-poke ratio $>1$ throughout the experiment.

Extinction training. An illustration of the general design of the extinction and reinstatement experiment is shown in Figure $1 c$. After their last LgA self-administration session, rats underwent $10 \mathrm{~d}$ of extinction training, using procedures similar to those described previously (De Vries et al., 1998; Shalev et al., 2002; Crombag et al., 2008). During these sessions, rats were taken from the animal colony, placed into test chambers, and attached to the infusion apparatus. The session proceeded in an identical manner to self-administration sessions, except that a nose poke into the active port activated the infusion pump without delivery of drug. Each extinction session was $1 \mathrm{~h}$ in length. After extinction sessions, rats underwent three $1 \mathrm{~h}$ pre-reinstatement sessions in which the rats were not connected to the infusion apparatus, and the operant chamber remained unlit for the entire session. Responses to either nose-poke port were recorded but had no other consequences. These sessions were conducted to further reduce the contribution of possible conditioned stimuli associated with drug delivery on responding (De Vries et al., 1998) and reduce possible contributions of novelty introduced by the operational changes between extinction sessions and reinstatement sessions.

Reinstatement testing. The following day (14 d after the last selfadministration session), rats were injected with saline intraperitoneally and immediately placed in the self-administration chamber for $2 \mathrm{~h}$. Similar to pre-reinstatement sessions, stimuli associated with drug delivery such as the attachment to the infusion line, house light, and infusion pump that might confound or potentiate reinstatement of drug-seeking behavior were not present for the duration of the session. Responses to the previously active and inactive nose pokes were recorded but had no consequence. The next day rats were tested for the reinstatement of drugseeking behavior by giving them a $10 \mathrm{mg} / \mathrm{kg}$ intraperitoneal injection of cocaine before placement into the test chamber. Thus, the first reinstatement test took place $15 \mathrm{~d}$ after the last self-administration session. Active and inactive nose pokes were recorded, although they had no consequence. The rats were then left undisturbed for an additional $30 \mathrm{~d}$, after which time the cocaine-priming reinstatement test was repeated as described above. Thus, the second test for reinstatement took place $45 \mathrm{~d}$ after the last self-administration session.

Fos immunohistochemistry. A subset of rats with self-administration and reinstatement experience were used for Fos immunochemistry ( $5 \mathrm{~s}$, $n=6 ; 45 \mathrm{~s}, n=10 ; 90 \mathrm{~s}, n=8$ ), and an additional 15 drug-naive control rats were used as controls for this portion of the study. These control rats were moved daily from the home colony room to holding chambers concurrently with rats undergoing self-administration training, where they were left undisturbed for $6 \mathrm{~h} / \mathrm{d}$ for an average of $10 \mathrm{~d}$. Control rats were matched with rats or groups of rats undergoing their final reinstatement test. During these days, control rats spent $2 \mathrm{~h}$ in their transport chambers, mirroring the length of the reinstatement session. All control rats received saline injections on the same day as rats undergoing reinstatement testing. The following day, some control rats received a second saline intraperitoneal injection $(n=5)$, whereas others $(n=10)$ received an acute $10 \mathrm{mg} / \mathrm{kg}$ intraperitoneal injection of cocaine. In this way, these control rats experienced the general effects of handing, transport, and time outside the animal colony in a distinctly different environment similar to self-administration rats (Ferrario et al., 2005). The control rats remained either drug naive or experienced a single acute exposure to cocaine equivalent to the dose and route of administration as the cocaine-priming injection used to reinstate cocaine-seeking behavior in rats that had undergone extinction training.

Immediately after the end of the second drug-primed reinstatement session or $2 \mathrm{~h}$ after injecting a transport control, rats were taken to a different room and deeply anesthetized with sodium pentobarbital (390 $\mathrm{mg} / \mathrm{kg}$, i.p.; Vortech) and transcardially perfused with $500 \mathrm{ml}$ of ice-cold perfusion rinse [ $73 \mathrm{~mm}$ sucrose, $18 \mathrm{~mm}$ procaine hydrochloride, and 139 mM sodium chloride in $0.1 \mathrm{M}$ sodium phosphate buffer (SPB), $\mathrm{pH} 7.4$ ], followed by $250 \mathrm{ml}$ of ice-cold paraformaldehyde rinse ( $4 \% \mathrm{w} / \mathrm{v}$ paraformaldehyde dissolved in $0.1 \mathrm{M}$ SPB buffer containing $73 \mathrm{~mm}$ sucrose, $\mathrm{pH}$ 7.4). Brains were removed and placed in $4 \%$ formaldehyde overnight at $4^{\circ} \mathrm{C}$ and then transferred to $30 \%(\mathrm{w} / \mathrm{v})$ sucrose for $3 \mathrm{~d}$ at the same temperature. Brains were coronally sectioned to a $40 \mu \mathrm{m}$ thickness with a freezing microtome. Series of sections were collected 120 or $160 \mu \mathrm{m}$ apart. Sections that were processed for immunohistochemistry within $2 \mathrm{~d}$ were stored in $0.1 \mathrm{M} \mathrm{SPB}$; otherwise, sections were stored at $-20^{\circ} \mathrm{C}$ in liquid cryoprotectant. Sections were processed for Fos and $\mu$-opioid receptor protein immunofluorescence in a similar manner to that by Reynolds and Berridge (2008). $\mu$-Opioid receptor expression was used to delineate the boundaries of the subregions of the nucleus accumbens (NAc) (Heimer et al., 1997). Sections were washed in $0.1 \mathrm{M}$ SPB containing $0.2 \%(\mathrm{v} / \mathrm{v})$ Triton X-100 with gentle agitation for $30 \mathrm{~min}$ and then pre-blocked for $30 \mathrm{~min}$ in a $5 \%(\mathrm{v} / \mathrm{v})$ normal donkey serum (NDS) solution. Sections were then incubated overnight with a primary antibody solution containing 1:500 goat polyclonal antibody raised against the $\mathrm{N}$ terminus of human Fos (sc-52-G; Santa Cruz Biotechnology) and 1:1000 rabbit polyclonal antibody raised against the $\mathrm{C}$ terminus of the rat 
$\mu$-opioid receptor 1 (ab10275; Abcam). After washing in $0.1 \mathrm{M}$ SPB for 30 min, sections were preblocked in a solution containing 5\% NDS and 5\% (v/v) Image-iT FX signal enhancer (Invitrogen) for $30 \mathrm{~min}$. Sections were subsequently incubated for $2 \mathrm{~h}$ in a solution containing 1:250 donkey anti-goat Alexa Fluor 488 antibody and 1:250 donkey anti-rabbit Alexa Fluor 594 antibody (Invitrogen) and 5\% signal enhancer. Next, sections were washed in SPB buffer and mounted, air dried, and coverslipped with Prolong Gold anti-fade reagent (Invitrogen). Control tissue stained with only secondary antibodies revealed little or no unspecific binding.

Visualization. Sections were visualized at $100 \times$ total magnification with a Leica DM6000B microscope with a Leica EL6000 external fluorescent light source coupled to a Q-Imaging monochrome 12-bit 1.4megapixel digital camera. Alexa Fluor 488 was fluoresced using a Leica L5 bandpass filter cube, and Alexa Fluor 594 was fluoresced using a TX2 bandpass filter cube. The same section and region was imaged for Fos and $\mu$-opioid immunoreactivity. Separate Fos and $\mu$-opioid images were captured as Lempel-Ziv-Welch lossless compression TIFF files to minimize image compression artifacts in dark-field areas of the image and were analyzed using the MCID Core 7.0/Analysis software package.

Sampling areas. The number of Fos-positive cells in the core and shell of the nucleus accumbens from the left and right hemispheres was summed together. The NAc shell and core were sampled at $+2.0 \mathrm{~mm}$ from bregma (Paxinos and Watson, 1998). An elliptical sampling area of $300 \times 650 \mu \mathrm{m}$ was used to sample the shell, and a smaller sampling area of $300 \times 450 \mu \mathrm{m}$ was used for the core. To better follow the contours of the shell and the core, sampling ellipses were angled.

Quantification. The number of Fos-positive cells was quantified by using the "autoscan utility," in which a maximum of five Fos-positive cells were visually identified in each image by the experimenter and sampled for hue and intensity values using a 4 - $\mu \mathrm{m}$-diameter sampling circle. The average value provided the threshold for identifying and quantifying Fos-positive nuclei in the image. In addition, a "target selection criteria" optimized to reduce the incidence of image artifacts contributing to the final count was used. Targets thus identified by the autoscan utility were then overlaid on the original unaltered Fos image and visually inspected to ensure fidelity in quantification and to minimize the contribution of artifacts toward the final cell count. In cases in which no Fos-positive nuclei could be identified in the section, Fos-positive nuclei from the cortex immediately adjacent to the striatum were used to set the target threshold. In all cases, the person quantifying the images was blind to the experimental conditions of each image.

Statistics. Behavioral data during LgA training sessions was analyzed as bins comprising the average of two contiguous daily sessions, because this reduced day-to-day variation and simplified data presentation. Data with repeated measures over sessions or time were analyzed using linear mixed-models (LMM) analysis using the SPSS 16 statistical package. For LMM analysis, the best-fitting model of repeated measures covariance was determined by the lowest Akaike information criterion score (West et al., 2007). Depending on the model selected, the degrees of freedom may have been adjusted to a non-integer value. If the LMM resulted in significance, mixed-model pairwise multiple comparisons of repeated measures means (Kowalchuk and Keselman, 2001) were used to test for group differences.

Behavioral and Fos immunohistochemistry analysis involving betweengroup comparisons were analyzed using one-way ANOVA or two-way ANOVA, followed by a Fisher's least significant difference post hoc test or one tailed $t$ tests, when appropriate.

\section{Results}

\section{Training}

Figure 2 shows the influence of gradually increasing the timeout interval during training on the number of active and inactive nose pokes $(a)$ and cocaine infusions $(b)$. During these training sessions, before being assigned to groups, all rats self-administered $0.4 \mathrm{mg} / \mathrm{kg}$ per infusion of cocaine delivered over $5 \mathrm{~s}$. There was no effect of progressively increasing the timeout interval on either active nose pokes $(p>0.05)$ or the number of infusions $(p>0.05)$.

In Figure $3 a$, Baseline indicates the mean number of active and inactive nose pokes $(a)$ and cocaine infusions $(b)$ averaged over

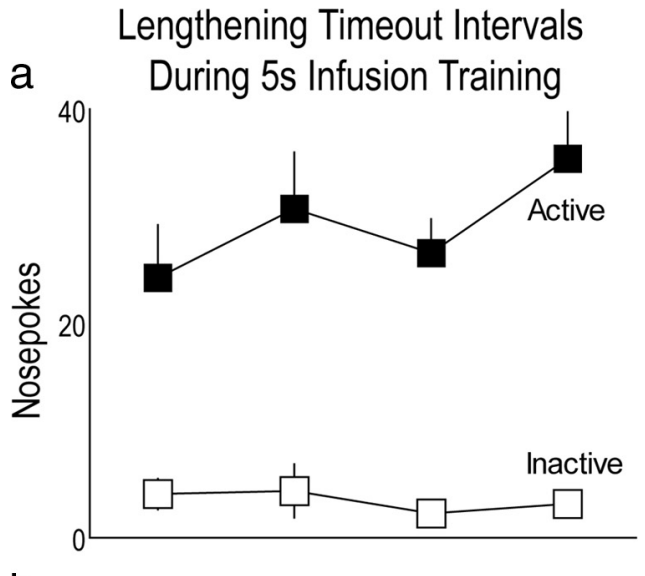

b 12

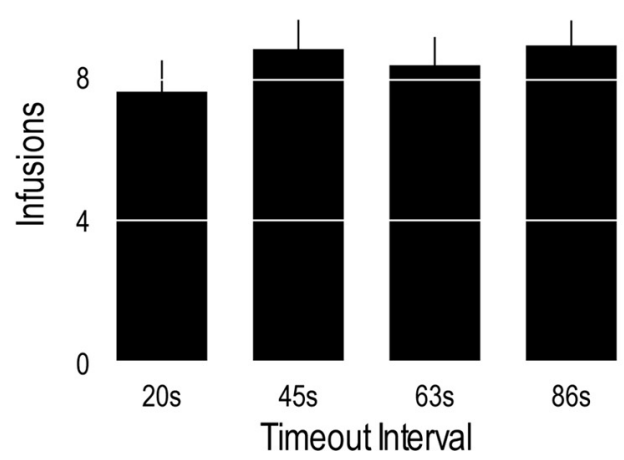

Figure 2. $\quad \boldsymbol{a}$, The mean \pm SEM number of active and inactive nose pokes made by all rats during self-administration training sessions before group assignment, in which timeout intervals were gradually lengthened. $\boldsymbol{b}$, The mean number of infusions made by all subjects during self-administration training sessions. During these training sessions, all rats received the cocaine infusion at the same speed (over $5 \mathrm{~s}$ ), and the timeout intervals were increased each time a rat reached criterion performance for self-administration. Data presented in the $85 \mathrm{~s}$ timeout sessions are the average of all subjects comprising the "Baseline" data point presented in Figure 3.

the last two training sessions when all rats received cocaine over $5 \mathrm{~s}$ and all had a $85 \mathrm{~s}$ timeout interval (these three groups represent rats that on the next day will receive cocaine at different rates). There was no effect of group $(p>0.05)$ or group $\times$ port interaction $(p>0.05)$ for nose pokes, although all groups made more active than inactive responses $\left(F_{(1,84)}=54.68, p<0.0001\right)$. There were also no significant group differences in the number of infusions during baseline $(p>0.05)$ (Fig. $3 b)$.

\section{Short-access sessions}

Figure $3 a$ also shows the number of nose pokes made during three daily ShA sessions (ShA1-ShA3) after rats were assigned to groups that received cocaine over 5,45 , or $90 \mathrm{~s}$. There was no significant effect of group, session, or a significant interaction (all $p$ values $>0.05$ ). Figure $3 b$ shows that, for the number of infusions, there were also no effects of group, session, or a group $\times$ session interaction (all $p$ values $>0.05$ ). Figure $3 c$ shows the number of infusions achieved by three representative subjects from each group during the last short-access session.

In summary, during ShA sessions, there was no significant effect of varying the rate of cocaine delivery between 5 and $90 \mathrm{~s}$ on selfadministration behavior, as assessed by either the number of active nose pokes or total infusions received during the session. This is consistent with our more extensive previous studies on the effect of 


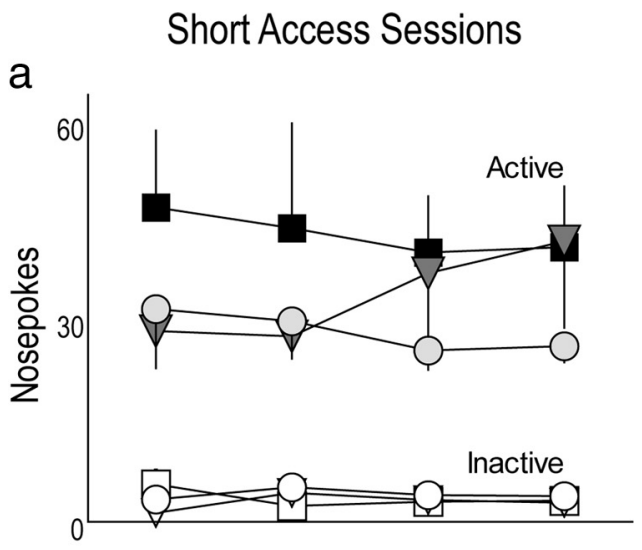

b

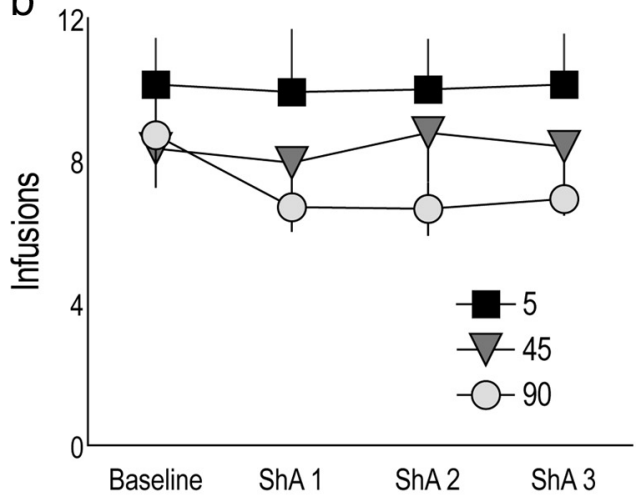

C

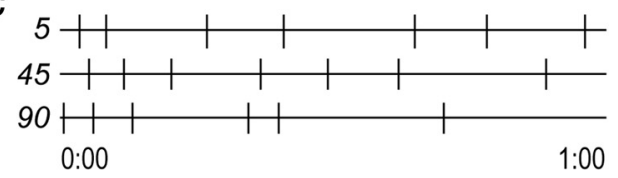

Figure 3. $\boldsymbol{a}$, The mean \pm SEM number of active and inactive nose pokes made during baseline training sessions, when all rats received cocaine at the same rate $(5 \mathrm{~s})$, and during short-access (ShA) sessions, when rats were assigned to groups that received cocaine over 5, 45, or $90 \mathrm{~s}$. Baseline data are averaged over two sessions. $\boldsymbol{b}$, The mean \pm SEM number of infusions received during the same baseline training and ShA sessions as in $\boldsymbol{a}$. $\boldsymbol{c}$, The pattern of selfadministration behavior in three representative rats during ShA session 3 . The horizontal line represents the duration of the session, and vertical marks indicate the time during the session when a rat self-injected cocaine.

rate of cocaine or amphetamine delivery on self-administration behavior under limited access conditions (Crombag et al., 2008).

\section{Long-access sessions}

Figure 4 shows the mean number of active nose pokes $(a)$ and cocaine infusions $(b)$ made by rats in each group when the session length was extended from $1 \mathrm{~h} / \mathrm{d}$ (ShA) to $6 \mathrm{~h} / \mathrm{d}$ (LgA). LgA sessions were analyzed as blocks of two daily sessions, and the average for the three ShA sessions is shown for comparison. Not surprisingly, all groups increased both their total number of nose pokes and infusions when the test session was extended from 1 to $6 \mathrm{~h} / \mathrm{d}$. To determine whether active nose pokes differed by group during LgA sessions, an overall LMM analysis with session blocks as a repeated measure was conducted on the number of active nose pokes during LgA sessions. There was an overall effect of group $\left(F_{(2,43)}=3.562, p<0.038\right)$ but no effect of session $(p>$ $0.05)$ and no interaction $(p>0.05)$. To determine how the groups differed from one another during LgA sessions, each group was compared using paired repeated effects LMM analysis. The 5 and $45 \mathrm{~s}$ groups made significantly more nose pokes than the $90 \mathrm{~s}$
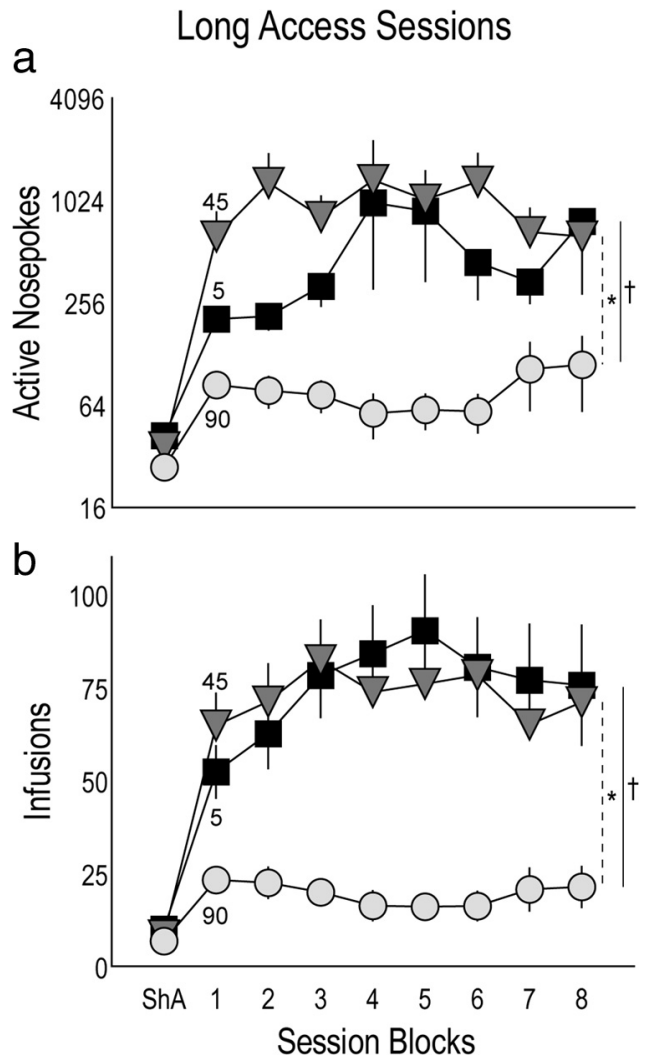

Figure 4. Shows the mean \pm SEM number of active nose pokes ( $\boldsymbol{a}$; note the $\log 10$ scale) and cocaine infusions $(\boldsymbol{b})$ made by rats receiving $0.4 \mathrm{mg} / \mathrm{kg}$ per infusion of cocaine over 5,45 , or $90 \mathrm{~s}$ after self-administration sessions were lengthened from 1 to $6 \mathrm{~h} / \mathrm{d}(\mathrm{LgA})$. LgA session data were analyzed as blocks of two daily sessions, and the average for the ShA sessions is shown for comparison. In $\boldsymbol{a},{ }^{\dagger} p<0.011$ for 5 versus 90 s; ${ }^{*} p<0.024$ for 45 versus 90 s. $\ln \boldsymbol{b},{ }^{\dagger} p<0.001$ for 5 versus 90 s and $p<0.004$ for interaction; ${ }^{*} p<0.001$ for 45 versus $90 \mathrm{~s}$.

group but did not differ from one another, although there was a trend for rats in the $45 \mathrm{~s}$ group to make more unrewarded responses during the timeout period than rats in the $5 \mathrm{~s}$ group.

For infusions (Fig. $4 b$ ), there was an overall effect of group $\left(F_{(2,45)}=13.986, p<0.001\right)$ but no effect of session $(p>0.05)$ and no group $\times$ session interaction $(p>0.05)$. The 5 and $45 \mathrm{~s}$ groups took significantly more infusions than the $90 \mathrm{~s}$ group but did not differ from one another $(p>0.05)$.

In summary, Figure 4 shows that, when given more time to take cocaine, rats given injections over 5 or $45 \mathrm{~s}$ markedly increased their number of nose pokes and associated cocaine intake and did so to a comparable extent. In striking contrast, rats given cocaine over $90 \mathrm{~s}$ only modestly increased their drug intake relative to what they took when drug was only available for $1 \mathrm{~h} / \mathrm{d}$. Indeed, rats in the 5 and $45 \mathrm{~s}$ groups increased their cocaine intake approximately eightfold when given a longer time to self-administer but, despite sixfold more time available to take cocaine, rats in the 90 s group only increased their intake approximately twofold.

\section{Within-session pattern of self-administration}

Figure $5 a$ shows that, during the LgA sessions, all rats in all groups discriminated between the active and inactive nosepoke ports. Figure 5 also illustrates the temporal pattern of self-administration behavior within LgA sessions. Figure $5 b$ shows that the 5 and $45 \mathrm{~s}$ groups maintained a stable and high rate of self-administration throughout the duration of LgA sessions. The cumulative infusions in the 90 s group was much lower than 
a
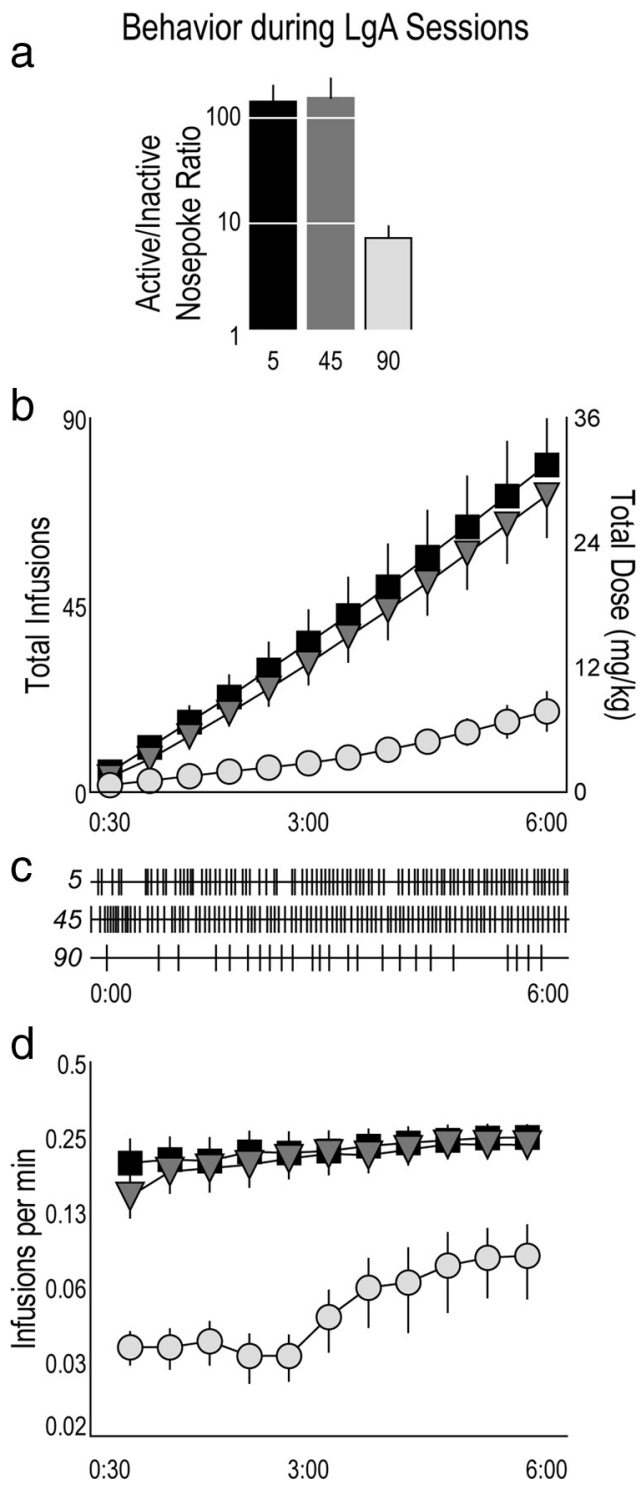

Figure 5. $\boldsymbol{a}$, The mean \pm SEM ratio of active to inactive nose pokes made by groups during long-access sessions. All groups discriminated between the active and inactive ports. $\boldsymbol{b}-\boldsymbol{d}$ show how self-administration behavior was distributed within the last six LgA sessions. $\boldsymbol{b}$, Mean \pm SEM cumulative infusions and total dose of cocaine self-administered by rats receiving cocaine over 5, 45, and 90 s during $6 \mathrm{~h} \mathrm{LgA}$ sessions. c, Infusions during LgA session 14 in the same three representative rats as shown in Figure $3 \boldsymbol{c}$. $\boldsymbol{d}$, The mean \pm SEM rate of self-administration (infusions per minute) within $\mathrm{LgA}$ sessions (note $\log 2$ scale).

in the other groups but did progressively increase as the session progressed (effect of session bin, $F_{(11,46)}=8.822, p<0.001$ ), indicating that rats in the $90 \mathrm{~s}$ group continued to take cocaine throughout the session. This is also illustrated in Figure $5 c$, which shows representative data from individual subjects (the same rats as in Fig. 3c). Finally, the rate of self-administration (infusions per minute) within sessions is shown in Figure $5 d$, confirming that the 5 and $45 \mathrm{~s}$ groups maintained a stable rate of self-administration for the duration of the session. In the $90 \mathrm{~s}$ group, the rate was even somewhat elevated in the last $3 \mathrm{~h}$ relative to the first $3 \mathrm{~h}$ of the session (effect of session bin, $F_{(10,13)}=4.365, p<0.009$ ). This is consistent with the small upward deflection seen in cumulative infusions during the latter half of the session. Thus, all groups continued to selfadminister cocaine throughout the duration of the $6 \mathrm{~h}$ sessions.

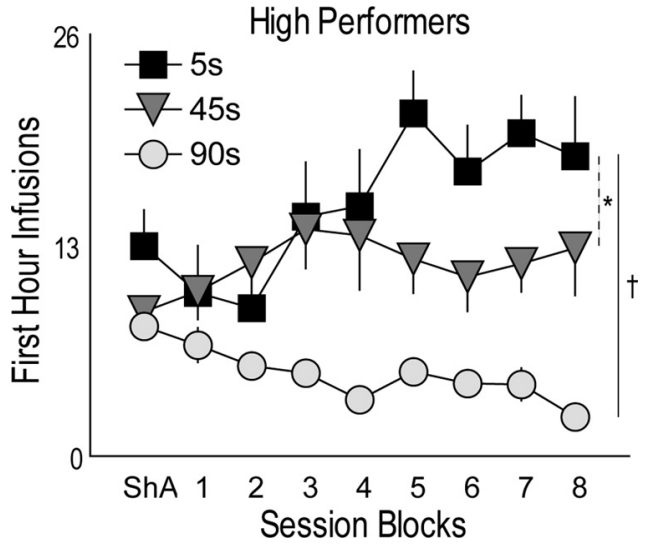

Figure 6. The mean \pm SEM number of infusions during the first hour of each session in high performers in each group, plotted over days of testing. High performers in each group were those that took above the median number of injections (top 50\%) during the first hour (averaged across all LgA sessions). ${ }^{*} p<0.05$ for 5 versus $45 \mathrm{~s} ;{ }^{\dagger} p<0.001$ for 5 versus 90 s and $p<$ 0.045 for interaction.

\section{Analysis of the first hour of the LgA sessions}

It has been reported that, when given extended access to cocaine, rats increase not only their total intake but, over time, they escalate the amount of drug they take during the first hour of each session (Ahmed and Koob, 1998, 1999; Ahmed et al., 2002). When all subjects were included in an analysis, rats in neither the 5 nor 45 s groups significantly escalated their number of infusions during the first hour of LgA sessions compared with ShA sessions (both $p$ values $>0.05$ ), and rats in the 90 s group actually decreased infusions in the first hour over days of testing $\left(F_{(8,104)}=\right.$ $10.429, p<0.001)$.

However, there was considerable individual variation in first hour of intake. Therefore, rats within each group were divided into "high performers" (top 50\%) and "low performers" (bottom $50 \%$ ), based on the total number of first-hour infusions during the last $8 \mathrm{~d}$ of LgA testing. The low performers in all groups showed a small decline in first-hour infusions across days of LgA testing (data not shown). In contrast, high performers (Fig. 6) in the $5 \mathrm{~s}$ group tended to increase their first hour of intake across days of testing $\left(F_{(8,37)}=2.122, p=0.058\right)$, whereas rats in the $45 \mathrm{~s}$ group showed no change across sessions $(p>0.05)$. The difference between the 5 and 45 s groups was statistically significant. This analysis suggests, therefore, that a subset of rats (high performers) given a $5 \mathrm{~s}$ infusion of cocaine escalated their first hour of cocaine intake to a greater extent than rats given cocaine over 45 or $90 \mathrm{~s}$.

\section{Extinction}

Figure 7 shows the number of active and inactive nose pokes by rats in each group during 10 sessions of extinction training. Active nose pokes are illustrated by symbols, whereas inactive nose pokes are shown as lines. There was a comparable decrease in active nose pokes over time in all groups (effect of session, $\left.F_{(9,43)}=2.584, p<0.019\right)$. Although it appears that rats in the $5 \mathrm{~s}$ group made more responses during extinction than those in the $90 \mathrm{~s}$ group, this was not statistically significant (effect of group and interaction, $p>0.05$ ).

First reinstatement test (15 d after the last self-administration session)

Figure $8 a$ shows the number of nose pokes after an intraperitoneal priming injection of either saline or cocaine given $15 \mathrm{~d}$ after the last self-administration session and extinction training. Ac- 


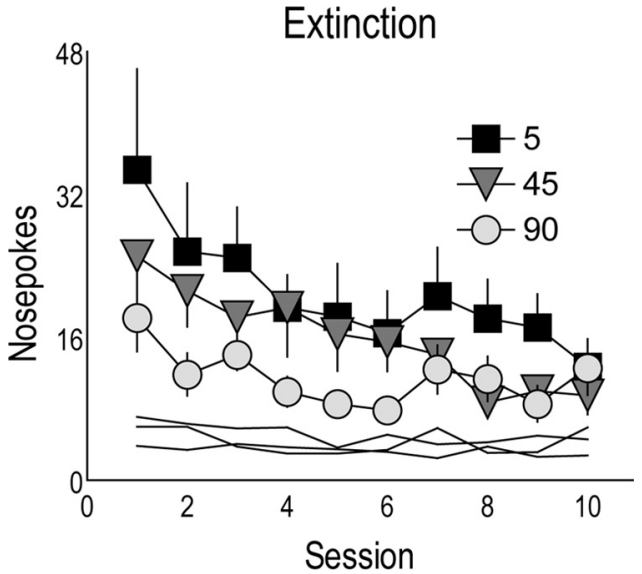

Figure 7. The mean \pm SEM number of nose pokes made by rats in each group during $10 \mathrm{~d}$ of extinction training when cocaine reward was not available. Active nose pokes are shown using symbols, and inactive nose pokes are depicted as lines.

tive nose pokes are represented by large bars, and inactive nose pokes are represented by inset bars. Rats in all groups reinstated responding after a cocaine-priming injection, as indicated by a significant increase in the number of active nose pokes, and there were no significant group differences in the degree of reinstatement [main effect of treatment, $F_{(1,84)}=9.403, p<0.004$; effect of rate of infusion (ROI) history and treatment $\times$ ROI history interaction, $p$ values $>0.05]$. There were no group differences in inactive nose pokes ( $p$ values $>0.05$ ).

\section{Second reinstatement test ( $45 \mathrm{~d}$ after the last self-administration session)}

Figure $8 b$ shows the number of nose pokes during the test for reinstatement conducted $45 \mathrm{~d}$ after the last self-administration session and $30 \mathrm{~d}$ after the first reinstatement session. For active nose pokes, a two-way ANOVA resulted in a significant main effect of treatment $\left(F_{(1,84)}=6.081, p<0.017\right)$ and ROI history $\left(F_{(2,84)}=3.991, p<0.023\right)$, and the treatment $\times$ ROI history interaction was almost significant $\left(F_{(2,84)}=2.967, p=0.057\right)$. To determine which groups reinstated responding active nose pokes after the cocaine prime were compared with those produced by an injection of saline. Only rats that previously received cocaine over $5 \mathrm{~s}$ showed significant reinstatement $\left(t_{(13)}=2.383, p<0.0167\right)$.

Similar to the first reinstatement test, there were no group differences in the number of inactive nose pokes. Note, however, that in all groups the number of active nose pokes after the saline injection were greater in this test than the first test for reinstatement (compare $a, b$ ), suggesting modest spontaneous recovery of responding.

\section{Fos immunoreactivity after cocaine priming}

Areas sampled are indicated by the gray areas in Figure 9a. Representative images showing Fos-positive cells and areas sampled within the nucleus accumbens core and shell are shown in Figure $9 b$. Figure $9 c$ illustrates the number of Fos-positive nuclei per square millimeter in the core and shell of the nucleus accumbens $2 \mathrm{~h}$ after an intraperitoneal priming injection of cocaine on the second reinstatement test day.

In the NAc shell, a one-way ANOVA on the number of Fospositive nuclei revealed a main effect of group $\left(F_{(4,34)}=3.901\right.$, $p<0.011)$. Relative to rats given saline, cocaine increased the number of Fos-positive cells in all groups, except in the $5 \mathrm{~s}$ group. The $45 \mathrm{~s}, 90 \mathrm{~s}$, and acute cocaine control groups did not differ from one another, and all showed significantly greater Fos ex-

\section{a Reinstatement 15 Days After SA}

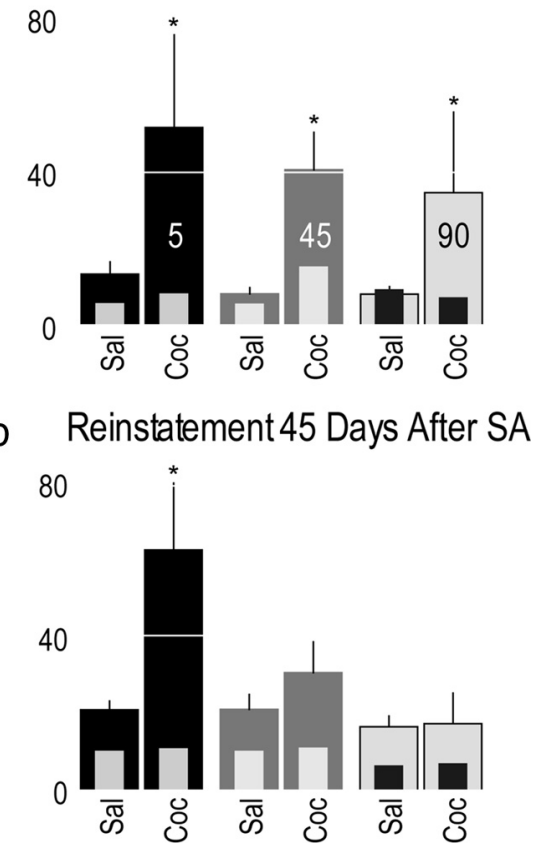

Figure 8. $\quad \boldsymbol{a}$ shows the mean \pm SEM number of nose pokes during the first reinstatement test, conducted 14-15 d after the last self-administration (SA) session, and $3 \mathrm{~d}$ after extinction training was completed. On day 14 , all rats received an intraperitoneal injection of saline (Sal) and the next day (day 15) an intraperitoneal injection of cocaine (Coc). ${ }^{*} p<0.004$, a main effect of cocaine treatment. $\boldsymbol{b}$ shows data from the second reinstatement test, which was conducted $45 \mathrm{~d}$ after the last self-administration session and $30 \mathrm{~d}$ after the first reinstatement test. The number of active nose pokes are represented by thick bars and inactive nose pokes by thin inset bars. ${ }^{*} p<0.0167$ for saline versus cocaine in the 5 s group, $t_{(13)}=2.383$.

pression than the $5 \mathrm{~s}$ group. For the NAc core, a one-way ANOVA also indicated there were significant group differences in the number of Fos-positive cells $\left(F_{(4,34)}=8.168, p<0.001\right)$. Compared with the saline control group, a cocaine injection increased the number of Fos-positive cells in the $45 \mathrm{~s}, 90 \mathrm{~s}$, and acute cocaine control group, and these groups did not differ from one another. In contrast, cocaine failed to increase Fos expression in the $5 \mathrm{~s}$ group, and the $5 \mathrm{~s}$ group had significantly fewer Fospositive cells than all the other groups given cocaine.

In summary, the ability of a cocaine challenge injection to induce Fos $45 \mathrm{~d}$ after the last self-administration session was markedly suppressed in rats with a history of self-administering cocaine injected over $5 \mathrm{~s}$ but not in rats with a history of selfadministering cocaine injected over either 45 or $90 \mathrm{~s}$. There is, therefore, at least one long-term change in the nucleus accumbens produced by a previous history with self-administered cocaine when it is administered rapidly (over $5 \mathrm{~s}$ ) that is not evident when it is administered more slowly (45-90 s).

\section{Discussion}

Few people who try drugs become addicted (Wagner and Anthony, 2002), and many factors influence addiction liability. Here we focused on one: how fast drug reaches the brain. The faster drugs reach the brain the greater the liability to addiction (Jones, 1990; Gorelick, 1992; Hatsukami and Fischman, 1996; Karch, 1999), although why this is so is not known. To determine whether variation in the rate of cocaine delivery influences selfadministration behavior, we varied the rate it was injected between 5 and $90 \mathrm{~s}$. This range captures rates that addicts report when injecting drugs (Zernig et al., 2003), approximates the difference in phar- 
a

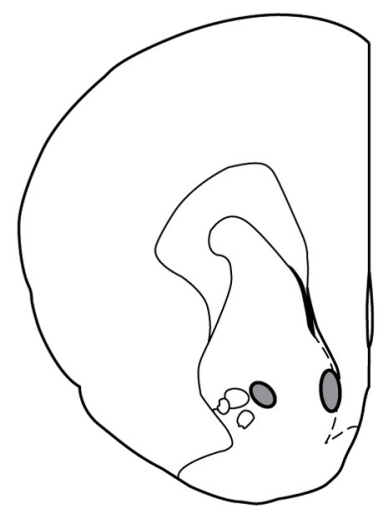

b
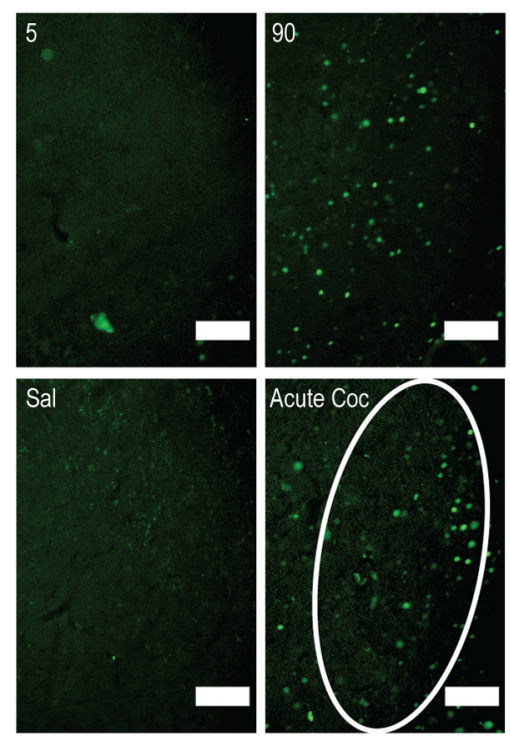

C

\section{0}

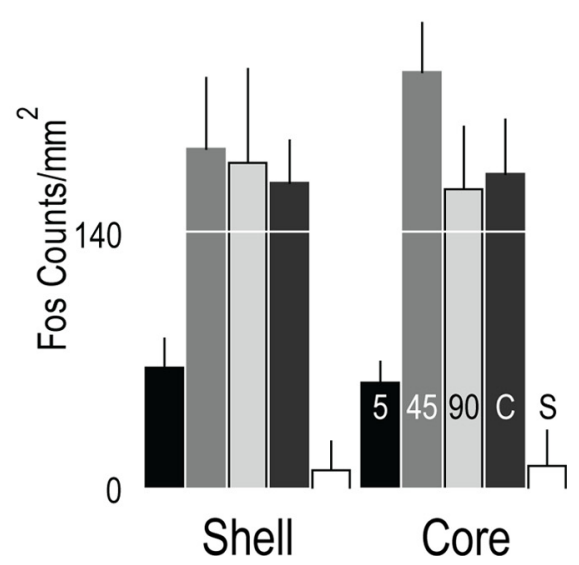

Figure 9. $a$, Areas of the core and shell divisions of the nucleus accumbens $+2.0 \mathrm{~mm}$ from bregma marked in gray that were sampled at the end of the reinstatement session $2 \mathrm{~h}$ after an intraperitoneal injection of $10 \mathrm{mg} / \mathrm{kg}$ cocaine. $\boldsymbol{b}$, Examples of Fos-positive nuclei in the shell of the nucleus accumbens +2.0 from bregma (Fos-positive nuclei are labeled green). At the start of the second reinstatement session, rats were given an intraperitoneal injection of saline or 10 $\mathrm{mg} / \mathrm{kg}$ cocaine, and brains were obtained $2 \mathrm{~h}$ later. The panels are from rats that had a history of cocaine self-administration, with cocaine delivered over 5 or $90 \mathrm{~s}$, and controls that received an intraperitoneal injection of saline (Sal) or an acute (first time) injection of cocaine (Acute $\mathrm{Coc}$ ). The shell division sampled within the nucleus accumbens is indicated by the white ellipse. Scale bars, $100 \mu \mathrm{m}$. c, The mean \pm SEM number of Fos-positive nuclei in the nucleus accumbens ( $+2.0 \mathrm{~mm}$ from bregma) core and shell subdivisions $2 \mathrm{~h}$ after an intraperitoneal injection of cocaine $(10 \mathrm{mg} / \mathrm{kg})$ in rats with a history of cocaine self-administration, when cocaine was delivered intravenously over 5,45 , or $90 \mathrm{~s}$. Control rats with no history of cocaine selfadministration were given an intraperitoneal injection of either saline $(S)$ or cocaine for the first macokinetics between snorting and smoking (Jones, 1990), and influences the subjective effects of cocaine (Abreu et al., 2001), while not influencing peak brain levels of cocaine (Samaha et al., 2002; Shou et al., 2006). We assessed self-administration first under limited access conditions $(1 \mathrm{~h} / \mathrm{d})$ and then when rats were given sixfold more time to take cocaine $(6 \mathrm{~h} / \mathrm{d})$. We then tested the ability of an intraperitoneal priming injection of cocaine to reinstate drugseeking behavior relatively soon after extended access selfadministration and again after a long period of abstinence.

\section{Rapid cocaine delivery promotes a large increase in drug intake only when rats are given extended access}

Varying the rate in cocaine delivery could influence selfadministration behavior because this introduces a delay between an action and the receipt of cocaine, which could theoretically impact its reinforcing effects. However, this does not seem to be the case under the conditions in this study, because there was only a modest and statistically insignificant effect of varying the rate of intravenous cocaine delivery between 5 and $90 \mathrm{~s}$ on drug intake under limited-access conditions $(1 \mathrm{~h} / \mathrm{d})$. This is consistent with previous studies in rats; variation in the rate of cocaine delivery over this range has no effects on the acquisition or maintenance of cocaine self-administration behavior, on progressive ratio performance, or on reinstatement (Pickens et al., 1969; Liu et al., 2005; Crombag et al., 2008). Furthermore, it is consistent with studies in rhesus monkeys in which varying the rate of cocaine delivery between 10 and $600 \mathrm{~s}$ had no effect on the $\mathrm{ED}_{50}$ for maintaining cocaine self-administration on a progressive ratio schedule (Woolverton and Wang, 2004). Similarly, rats selfadminister nicotine delivered over a wide range of speeds and, in fact, prefer slower speeds (Sorge and Clarke, 2009). Thus, as concluded by Liu et al. (2005, p 195), "injection duration did not have profound effects on the acute reinforcing effects of cocaine" (see also Pickens et al., 1969; Crombag et al., 2008).

However, when given more opportunity to take cocaine, there was a striking effect on the amount of drug consumed. When given sixfold more time to take drug, rats receiving cocaine rapidly (5-45 s) increased their intake eightfold. In contrast, when cocaine was delivered over $90 \mathrm{~s}$, rats increased their intake only twofold. This suggests that the rate that drug reaches the brain is a major factor influencing escalation of use, an important symptom of addiction. Given that this escalation in intake is not because rapid injections are simply more reinforcing, there must be another mechanism.

Rats that in the past experienced rapidly delivered cocaine show greater reinstatement after a long period of abstinence In addition to escalation of intake, another symptom of addiction is a high propensity to relapse. We found that, after a short period of abstinence (15 d), an intraperitoneal drug "prime" reinstated responding in all groups, but, after a longer period of abstinence ( $45 \mathrm{~d})$,

$\leftarrow$

time (C). This test was conducted $45 \mathrm{~d}$ after the last self-administration session. In the NAc shell, a cocaine-priming injection produced greater Fos expression compared with the saline control group in all groups except the $5 \mathrm{~s}$ group ( $45 \mathrm{~s}, p<0.004 ; 90 \mathrm{~s}, p<0.007$; acute cocaine control group, $p<0.008)$. The $45 \mathrm{~s}, 90 \mathrm{~s}$, and acute cocaine groups did not differ from each other, and these groups all showed significantly greater Fos expression than the $5 \mathrm{~s}$ group ( $5 \mathrm{vs} 45 \mathrm{~s}, p<$ $0.028 ; 5$ vs $90 \mathrm{~s}, p<0.047 ; 5$ s vs acute cocaine control, $p=0.059)$. In the NAc core, only the $45 \mathrm{~s}$ $(p<0.001), 90 \mathrm{~s}(p<0.02)$, and acute cocaine $(p<0.02)$ groups had greater Fos expression compared with the saline control group. The 5 s group did not have greater Fos expression than saline control ( $p>0.05$ ) and had significantly fewer Fos-positive cells than all other groups given cocaine-priming injections ( $p$ values $<0.02$ ). 
only rats that previously had cocaine injected over $5 \mathrm{~s}$ reinstated responding.

It is not clear why after prolonged abstinence only rats that previously experienced cocaine delivered over $5 \mathrm{~s}$ reinstated drug-seeking, but it is possible that rapid drug delivery produces more persistent changes in brain systems that mediate the incentive motivational effects of drugs. Consistent with this hypothesis, we found group differences in the ability of the intraperitoneal cocaine prime to induce the expression of the immediate early gene c-fos in the nucleus accumbens. Repeated exposure to cocaine produces a marked desensitization in its ability to induce Fos protein (Daunais and McGinty, 1994; Daunais et al., 1995; Moratalla et al., 1996; Ben-Shahar et al., 2004; Zahm et al., 2010), and here this effect persisted only in rats with a history of $5 \mathrm{~s}$ infusions. In rats that previously received cocaine over 45 or $90 \mathrm{~s}$, the cocaine prime induced similar Fos expression in the nucleus accumbens as in drug-naive controls. We have seen a similar effect of rate of infusion after the repeated administration of nicotine (Samaha et al., 2005). This result suggests that rapidly administered cocaine has more persistent effects on both brain and on behavior than when cocaine reaches the brain even a little slower. Furthermore, the persistent effect of rapidly administered cocaine is not just a consequence of the amount of drug previously taken, because rats in the 5 and $45 \mathrm{~s}$ groups did not differ in total drug intake.

How persistent desensitization of cocaine-induced Fos expression might contribute to an increased propensity to reinstatement is unknown, and there may be no causal relationship. Chronic cocaine does result in an accumulation of the transcription factor $\Delta$ FosB (Hope et al. 1994; Kelz et al., 1999; Colby et al., 2003; McClung et al., 2004), and $\Delta$ FosB can suppress the transcription of c-fos mRNA through chromatin remodeling (Renthal et al., 2008). Perhaps the persistent desensitization of c-fos after $5 \mathrm{~s}$ injections reflects a continued elevation in $\Delta$ FosB, which is thought to be important in addiction (Nestler, 2001). However, this is highly speculative and the mechanism responsible for the influence of speed of cocaine delivery on the escalation in intake and persistent susceptibility to reinstatement described here remains to be determined.

Although these experiments do not establish why the rate of cocaine delivery had such a profound effect on the amount of drug intake and susceptibility to reinstatement, we can exclude some obvious potential causes. First, the long "timeout" interval did not constrain self-administration behavior (Fig. 2), and all rats had exactly the same opportunity to take drug. It is not surprising that the $90 \mathrm{~s}$ interval required between injections had no effect on self-administration behavior because this is far shorter than the "self-imposed" inter-infusion interval seen under these conditions, which is $\sim 4 \mathrm{~min}$ (Mantsch et al., 2001; Ferrario et al., 2005; Crombag et al., 2008; Belin et al., 2009). Another possibility is that the amount of drug to reach the brain varies across these infusion rates, but this is not the case. Varying the rate of intravenous cocaine delivery between 5 and 100 s has no effect on peak brain levels of cocaine (Samaha et al., 2002, their Fig. 1; Shou et al., 2006; Schindler et al., 2009); all that differs is the time to reach peak. This is consistent with the observation that the peak amount of dopamine overflow in the striatum measured with rapid microdialysis sampling is the same in rats administered intravenous cocaine over 5 or 100 s (Ferrario et al., 2008).

\section{Implications for addiction}

Whatever the underlying mechanism, our results establish that, when provided with the opportunity to take large amounts of drug, the rapid delivery of cocaine preferentially produces a marked escalation in intake. This could obviously account for why cocaine is more addictive when it reaches the brain rapidly, for example, when it is smoked rather than snorted (Jones, 1990; Hatsukami and Fischman, 1996). An escalation of intake would result in the brain being exposed to much larger amounts of drug, which presumably would further facilitate many different changes in the body and brain that could contribute to addiction. There are many classes of adaptations that could be involved, from homeostatic adaptations related to tolerance to those related to incentive sensitization. Consistent with the latter, the rapid administration of cocaine and nicotine facilitates the development of psychomotor sensitization and therefore the associated changes in brain responsible for this form of experience-dependent plasticity (Samaha et al., 2002, 2005). Furthermore, when administered acutely, the rapid administration of cocaine (Samaha et al., 2004) and nicotine (Samaha et al., 2005) is more effective in inducing c-fos and arc mRNA in mesocorticolimbic structures and even engages different cells and circuits than when administered even a little slower (Kiyatkin and Brown, 2005). Therefore, it is possible that rapid injections promote adaptations in brain regions that mediate incentive motivation for drug, increasing the degree to which the drug is "wanted," further increasing intake.

In conclusion, we suggest that cocaine is potentially more addictive when taken in forms or routes that result in its rapid entry into the brain because (1) this promotes a marked escalation in drug intake and (2) it renders individuals more susceptible to relapse, even long after the discontinuation of drug use. These effects are presumably because the rapid delivery of cocaine promotes persistent changes in brain systems that regulate motivation for drug, and the continuing exposure to high levels of drug may result in a vicious cycle that further promotes maladaptive changes in brain and behavior.

\section{References}

Abreu ME, Bigelow GE, Fleisher L, Walsh SL (2001) Effect of intravenous injection speed on responses to cocaine and hydromorphone in humans. Psychopharmacology (Berl) 154:76-84.

Ahmed SH, Koob GF (1998) Transition from moderate to excessive drug intake: change in hedonic set point. Science 282:298-300.

Ahmed SH, Koob GF (1999) Long-lasting increase in the set point for cocaine self-administration after escalation in rats. Psychopharmacology (Berl) 146:303-312.

Ahmed SH, Kenny PJ, Koob GF, Markou A (2002) Neurobiological evidence for hedonic allostasis associated with escalating cocaine use. Nat Neurosci 5:625-626.

Balster RL, Schuster CR (1973) Fixed-interval schedule of cocaine reinforcement: effect of dose and infusion duration. J Exp Anal Behav 20:119-129.

Belin D, Balado E, Piazza PV, Deroche-Gamonet V (2009) Pattern of intake and drug craving predict the development of cocaine addiction-like behavior in rats. Biol Psychiatry 65:863-868.

Ben-Shahar O, Ahmed SH, Koob GF, Ettenberg A (2004) The transition from controlled to compulsive drug use is associated with a loss of sensitization. Brain Res 995:46-54.

Ben-Shahar O, Posthumus EJ, Waldroup SA, Ettenberg A (2008) Heightened drug-seeking motivation following extended daily access to selfadministered cocaine. Prog Neuropsychopharmacol Biol Psychiatry 32: 863-869.

Brown PL, Kiyatkin EA (2005) Brain temperature change and movement activation induced by intravenous cocaine delivered at various injection speeds in rats. Psychopharmacology (Berl) 181:299-308.

Colby CR, Whisler K, Steffen C, Nestler EJ, Self DW (2003) Striatal cell type-specific overexpression of $\Delta$ FosB enhances incentive for cocaine. J Neurosci 23:2488-2493.

Crombag HS, Badiani A, Robinson TE (1996) Signalled versus unsignalled intravenous amphetamine: large differences in the acute psychomotor response and sensitization. Brain Res 722:227-231.

Crombag HS, Ferrario CR, Robinson TE (2008) The rate of intravenous 
cocaine or amphetamine delivery does not influence drug-taking and drug-seeking behavior in rats. Pharmacol Biochem Behav 90:797-804.

Daunais JB, McGinty JF (1994) Acute and chronic cocaine administration differentially alters striatal opioid and nuclear transcription factor mRNAs. Synapse 18:35-45.

Daunais JB, Roberts DC, McGinty JF (1995) Short-term cocaine self administration alters striatal gene expression. Brain Res Bull 37:523-527.

Deroche-Gamonet V, Belin D, Piazza PV (2004) Evidence for addiction-like behavior in the rat. Science 305:1014-1017.

De Vries TJ, Schoffelmeer AN, Binnekade R, Mulder AH, Vanderschuren LJ (1998) Drug-induced reinstatement of heroin- and cocaine-seeking behaviour following long-term extinction is associated with expression of behavioural sensitization. Eur J Neurosci 10:3565-3571.

Ferrario CR, Gorny G, Crombag HS, Li Y, Kolb B, Robinson TE (2005) Neural and behavioral plasticity associated with the transition from controlled to escalated cocaine use. Biol Psychiatry 58:751-759.

Ferrario CR, Shou M, Samaha AN, Watson CJ, Kennedy RT, Robinson TE (2008) The rate of intravenous cocaine administration alters c-fos mRNA expression and the temporal dynamics of dopamine, but not glutamate, overflow in the striatum. Brain Res 1209:151-156.

Gorelick DA (1992) Progression of dependence in male cocaine addicts. Am J Drug Alcohol Abuse 18:13-19.

Gorelick DA (1998) The rate hypothesis and agonist substitution approaches to cocaine abuse treatment. Adv Pharmacol 42:995-997.

Hatsukami DK, Fischman MW (1996) Crack cocaine and cocaine hydrochloride. Are the differences myth or reality? JAMA 276:1580-1588.

Heimer L, Alheid GF, de Olmos JS, Groenewegen HJ, Haber SN, Harlan RE, Zahm DS (1997) The accumbens: beyond the core-shell dichotomy. J Neuropsychiatry Clin Neurosci 9:354-381.

Hope BT, Nye HE, Kelz MB, Self DW, Iadarola MJ, Nakabeppu Y, Duman RS, Nestler EJ (1994) Induction of a long-lasting AP-1 complex composed of altered Fos-like proteins in brain by chronic cocaine and other chronic treatments. Neuron 13:1235-1244.

Jones RT (1990) The pharmacology of cocaine smoking in humans. NIDA Res Monogr 99:30-41.

Karch SB (1999) Cocaine: history, use, abuse. J R Soc Med 92:393-397.

Kato S, Wakasa Y, Yanagita T (1987) Relationship between minimum reinforcing doses and injection speed in cocaine and pentobarbital selfadministration in crab-eating monkeys. Pharmacol Biochem Behav 28:407-410.

Kelz MB, Chen J, Carlezon WA Jr, Whisler K, Gilden L, Beckmann AM, Steffen C, Zhang YJ, Marotti L, Self DW, Tkatch T, Baranauskas G, Surmeier DJ, Neve RL, Duman RS, Picciotto MR, Nestler EJ (1999) Expression of the transcription factor deltaFosB in the brain controls sensitivity to cocaine. Nature 401:272-276.

Kiyatkin EA, Brown PL (2005) Dopamine-dependent and dopamineindependent actions of cocaine as revealed by brain thermorecording in freely moving rats. Eur J Neurosci 22:930-938.

Kowalchuk RK, Keselman HJ (2001) Mixed-model pairwise multiple comparisons of repeated measures means. Psychol Methods 6:282-296.

Liu Y, Roberts DC, Morgan D (2005) Sensitization of the reinforcing effects of self-administered cocaine in rats: effects of dose and intravenous injection speed. Eur J Neurosci 22:195-200.

Mantsch JR, Ho A, Schlussman SD, Kreek MJ (2001) Predictable individual differences in the initiation of cocaine self-administration by rats under extended-access conditions are dose-dependent. Psychopharmacology (Berl) 157:31-39.

McClung CA, Ulery PG, Perrotti LI, Zachariou V, Berton O, Nestler EJ (2004) DeltaFosB: a molecular switch for long-term adaptation in the brain. Brain Res Mol Brain Res 132:146-154.

Moratalla R, Elibol B, Vallejo M, Graybiel AM (1996) Network-level changes in expression of inducible Fos-Jun proteins in the striatum during chronic cocaine treatment and withdrawal. Neuron 17:147-156.

Nelson RA, Boyd SJ, Ziegelstein RC, Herning R, Cadet JL, Henningfield JE, Schuster CR, Contoreggi C, Gorelick DA (2006) Effect of rate of administration on subjective and physiological effects of intravenous cocaine in humans. Drug Alcohol Depend 82:19-24.

Nestler EJ (2001) Molecular neurobiology of addiction. Am J Addict 10:201-217

O’Brien MS, Anthony JC (2005) Risk of becoming cocaine dependent: epidemiological estimates for the United States, 2000-2001. Neuropsychopharmacology 30:1006-1018.
Panlilio LV, Goldberg SR, Gilman JP, Jufer R, Cone EJ, Schindler CW (1998) Effects of delivery rate and non-contingent infusion of cocaine on cocaine self-administration in rhesus monkeys. Psychopharmacology (Berl) 137: 253-258.

Paxinos G, Watson C (1998) The rat brain in stereotaxic coordinates, Ed 4. New York: Academic.

Pelloux Y, Everitt BJ, Dickinson A (2007) Compulsive drug seeking by rats under punishment: effects of drug taking history. Psychopharmacology (Berl) 194:127-137.

Pickens R, Dougherty J, Thompson T (1969) Effects of volume and duration of infusion on cocaine reinforcement with concurrent activity recording. In: Minutes of the Meeting of the Committee on Problems of Drug Dependence, pp 5805-5811. Washington, DC: National Academy of Science/National Research Council.

Renthal W, Carle TL, Maze I, Covington HE 3rd, Truong HT, Alibhai I, Kumar A, Montgomery RL, Olson EN, Nestler EJ (2008) $\Delta$ FosB mediates epigenetic desensitization of the c-fos gene after chronic amphetamine exposure. J Neurosci 28:7344-7349.

Resnick RB, Kestenbaum RS, Schwartz LK (1977) Acute systemic effects of cocaine in man: a controlled study by intranasal and intravenous routes. Science 195:696-698.

Reynolds SM, Berridge KC (2008) Emotional environments retune the valence of appetitive versus fearful functions in nucleus accumbens. Nat Neurosci 11:423-425.

Samaha AN, Robinson TE (2005) Why does the rapid delivery of drugs to the brain promote addiction? Trends Pharmacol Sci 26:82-87.

Samaha AN, Li Y, Robinson TE (2002) The rate of intravenous cocaine administration determines susceptibility to sensitization. J Neurosci 22:3244-3250.

Samaha AN, Mallet N, Ferguson SM, Gonon F, Robinson TE (2004) The rate of cocaine administration alters gene regulation and behavioral plasticity: implications for addiction. J Neurosci 24:6362-6370.

Samaha AN, Yau WY, Yang P, Robinson TE (2005) Rapid delivery of nicotine promotes behavioral sensitization and alters its neurobiological impact. Biol Psychiatry 57:351-360.

Schindler CW, Panlilio LV, Thorndike EB (2009) Effect of rate of delivery of intravenous cocaine on self-administration in rats. Pharmacol Biochem Behav 93:375-381.

Shalev U, Grimm JW, Shaham Y (2002) Neurobiology of relapse to heroin and cocaine seeking: a review. Pharmacol Rev 54:1-42.

Shou M, Ferrario CR, Schultz KN, Robinson TE, Kennedy RT (2006) Monitoring dopamine in vivo by microdialysis sampling and on-line CE-laserinduced fluorescence. Anal Chem 78:6717-6725.

Sorge RE, Clarke PB (2009) Rats self-administer intravenous nicotine delivered in a novel smoking-relevant procedure: effects of dopamine antagonists. J Pharmacol Exp Ther 330:633-640.

Vanderschuren LJ, Everitt BJ (2004) Drug seeking becomes compulsive after prolonged cocaine self-administration. Science 305:1017-1019.

Wagner FA, Anthony JC (2002) From first drug use to drug dependence; developmental periods of risk for dependence upon marijuana, cocaine, and alcohol. Neuropsychopharmacology 26:479-488.

Weeks J (1972) Long-term intravenous infusions. In: Methods in psychobiology (Meyer RD, ed), pp 155-168. London: Academic.

West BW, Welch KB, Galecki AT (2007) Linear mixed models: a practical guide using statistical software, Ed 2. Boca Raton, FL: Chapman and Hill/CRC.

Woolverton WL, Wang Z (2004) Relationship between injection duration, transporter occupancy and reinforcing strength of cocaine. Eur J Pharmacol 486:251-257.

Zahm DS, Becker ML, Freiman AJ, Strauch S, Degarmo B, Geisler S, Meredith GE, Marinelli M (2010) Fos after single and repeated self-administration of cocaine and saline in the rat: emphasis on the basal forebrain and recalibration of expression. Neuropsychopharmacology 35:445-463.

Zernig G, Giacomuzzi S, Riemer Y, Wakonigg G, Sturm K, Saria A (2003) Intravenous drug injection habits: drug users' self-reports versus researchers' perception. Pharmacology 68:49-56.

Zhang D, Zhang L, Tang Y, Zhang Q, Lou D, Sharp FR, Zhang J, Xu M (2005) Repeated cocaine administration induces gene expression changes through the dopamine D1 receptors. Neuropsychopharmacology 30:1443-1454.

Zhang J, Zhang L, Jiao H, Zhang Q, Zhang D, Lou D, Katz JL, Xu M (2006) c-Fos facilitates the acquisition and extinction of cocaine-induced persistent changes. J Neurosci 26:13287-13296. 